\section{The Economic Status of the Engineer}

\author{
By R. W. SORENSEN
}

Synopsis: This is not a committee report, though perhaps it could be made to serve as such, because its genesis was a request from the committee on the economic status of the engineer that a paper be written around the author's remark, "The economic status of the engineer is largely a matter determined by each individual engineer according to his particular personal qualifications and the relations these bear to the work he does and to the personalities of those persons with whom and by whom he is employed."

The study on which the paper is based shows conclusions which may be briefed as follows:

Engineers, through suffering considerable loss of income and employment during the recent years of business depression, on the whole have fared much better than most classification groups, be they government, capital, profession, or labor.

Preceding the depression, there was no lack of employment for engineers and their compensation for the most part was equitable in comparison with the pay for other types of service.

The verdict of users of engineering service regarding the reasons why engineers who have not made satisfactory progress professionally or in their economic status is almost unanimous that such failures are due to deficiencies in personality, failures are due to deficiencies in personality, genlack of technical training.

Graduation from college is prerequisite to success in engineering, but does not per se guarantee an engineer.

The education obtained by taking engineering courses and engaging in the practice of engineering for most of those who have chosen the routes theref has led to "the more abundant life" and a better economic status than the lots of the families from economic status than the lots
which engineers have come.

If the writer were not a pedagogue, this summary and the list of references would probably constitute the entire paper, because most of the readers will probably have time for reading only the summary. The readers whose engineering conscience will not permit ready acceptance of unsupported statements, will be burdened with the urge to read not only the entire paper but will have a desire to consider all the information available publications afford. In writing the paper, much use has been made of data in bulletins published by the Bureau of Labor Statistics. In this paper these are called bulletins or noted by numbers. For a complete list of these bulletins see footnote to article, "Sources of Engineering Income, 1929-1934," page 1353 in ElECTRICAL ENGINEERING, volume 56, November 1937.

$\mathbf{T}$ HE ECONOMIC status of the engineer is bifunctional in its scope-one part deals with the value of the integrated work which all engineers have contributed to the progress and welfare of mankind; the other part has to do with economic recognition in the way of social position and salary which engineers and their families receive in return for service

Electrical Engineering in the September 1932 number announced for the first time the appointment of a committee to be known as the "committee on the economic status of the engineer." The function of that committee is set forth in Institute by-laws, article III, section 83 , which says this committee "shall consist of five members, and shall consider matters relating to the position, function, and responsibility of the engineer in the development of human welfare, and make reports and recommendations to the board of directors thereupon. The committee shall co-operate with similar committees of other engineering societies, and shall also consider and report upon all matters referred to it by the board of directors, the president, and the national secretary." The language of this article shows wisdom in its formulation and clearly charges the committee with the duty of keeping informed and advising the members of the Institute, through its board of directors, of ways and means whereby they may be of service to mankind. Such responsibility would be overwhelming, were it not for the fact that all engineering aims at exactly the goal specified.

The world's economic evolution has resulted in much classification of the workers responsible for changing the habits of its citizens from those of the jungle to our present complex but regal standard of living, though jumbled be its attendant economic program under which we are muddling along.

One group of these workers is known as the professional men's group. Professional men are, perhaps, best defined by saying they are men who have professional education; that is, "the training that fits men for special vocations in which science is applied to the practical purposes of life. It supposes, as its basis, the knowledge and discipline which general culture affords."

Many attempts have been made to write an all-inclusive definition for the engineer, but the rapid march of time has

Paper number 38-88 recommended by the AIEE committee on education and presented at the AIEE committee on education and presented at the AIEE summer convention, Washington, D. C., June 20-
24, 1938. Manuscript submitted March 16, 1938; made available for preprinting May 31,1938 .

R. W. Sorensen is professor and head of the department of electrical engineering, California Institute of Technology, Pasadena. rendered. made each effort obsolete, even as the progressive science of engineering rather than the wearing out of machines has relegated many engineering products to the oblivion of the obsolete.

Engineers qualify as professional men by having professional education. Government research as to the "Educational Qualifications in the Engineering Profession," shows, as set forth in Bulletin R-400:

"A first degree in engineering is now almost a prerequisite in order to obtain professional status and a position. Postgraduate work, however, is important only in a few of the professional classes. The tendency of engineers to transfer from the course of college specialization to other classes of work is negligible. These are a few of the facts developed in the survey of the engineering profession, which was undertaken by the Bureau of Statistics in May 1935, at the request of the American Engineering Council."

Figures on which the above statements are based show that only 1.52 per cent of the engineers who began practice between 1930 and 1934 were not graduates. For all years up to $1929,27.6$ per cent of all engineers were not graduates. For all years up to $1935,17.7$ per cent of all engineers were not graduates. For all years up to $1935,13.3$ per cent of all electrical engineers were not graduates. Also the number of engineering graduates with more than one degree is very small, viz., $1 / 2$ per cent and $1 / 10$ per cent only having respectively masters' and doctorate degrees.

The doubt expressed as to the importance of postgraduate work is challenged, because graduate work in engineering colleges is too new to provide enough statistical data to draw conclusions as to its value. There is strong evidence, however, that men who are qualified for and have completed graduate courses which are provided in properly manned and wellequipped colleges for the study of modern science and mathematics as applied to engineering, have, for the most part, advanced in professional status at rates which show justification for graduate work. In the author's opinion, the limited number of men who have the special scientific and mathematical ability to warrant the continuation of postgraduate work unto the earning of a doctorate degree (and no others) should be encouraged toward that end.

A poet scanning these data and writing in Biblical language might well say, "It is easier for a camel to go through the eye of a needle than for a man to become an engineer without the advantage of graduation from an engineering college," or expressed in current language of the street, it may be said, "The odds are better than 98 to one you can't be an engineer without graduation." 
In fact the engineer finds that graduation does not end study, but that he must supplement his practice by continued study else he will lag behind just in proportion as his interest in research and study wanes. Perhaps, therefore, it will be easier to determine who are engineers by the manner in which they do their work, rather than to judge by graduation, license to practice, by passing examinations, often irrelevant to the kind of engineering done.

The law says a boy becomes a man the day te is 21 years old, but, except for legal privileges and voting, no change takes place on the 21st birthday, but rather a boy becomes a man when he puts away childish things and meets his problems in a manly way.

So with beccming an engineer. A man does not become an engineer because he graduates, or because he completes a test course and becomes a good draughtsman, mechanic, calculator, designer, or professor of electrical engineering. He becomes an engineer when he diligently and intelligently uses his God-given and hereditary talents, his education, his environment, his background, and his personality to produce new ideas and, through the medium of the crafts mentioned, finds ways and means for putting these ideas to work and makes a scientific analysis of his procedure in order that he may proceed by the engineering method rather than by cut-and-try or empirical methods.

Engineers, perforce, must at once be very co-operative and very individualistic. The co-operative characteristic is necessary because engineering problems of today are too large for one man to solve, and must be worked out by groups of men working in such close relationship as often to make practically impossible any acknowledgment as to the source of key ideas which unlock the problem solutions. Engineers must be individualists in order that each may contribute his share to the profession, by discovering in the daily tasks performed, new problems and their solutions. As illustrative of the latter point, consider the 27 Edison Medalists, beginning with Elihu Thompson and including the most recent one, Gano Dunn. No two of the entire 27 have traveled even similar paths to success. In fact, in all engineering history there are probably no case records which show that two engineers have done identical work, even in instances where promotions and other causes have made vacancies in organization that result in succession appointments.

Thus we see that engineers in their re- lations with their work and fellow men have true professional status in that the particular contributions of each engineer to society are unique.

The other phase of the economic status of engineers, bluntly stated, is to what extent does all this work enable them to provide themselves and their families with good social positions and the use of the facilities for human betterment which engineers have made available. This part of the question, while not specifically mentioned in the Institute by-laws, is implied by the name of the committee, and committee consideration thereof is expected by the Institute members.

Statistical data regarding employment and income are now available in bulletins published by the United States Department of Labor, Bureau of Labor Statistics. Parts of the data in these bulletins have been published in Electrical ENGINEERING.

A study of these data and much other information obtained from the printed page, by discussion with others, and by experience on the part of the author, seems to warrant the conclusion that the economic status of engineers in comparison to that of other citizens is for the most part reasonably equitable, though many engineers are of the opinion that the members of the engineering profession have received less reward than their work warrants.

Bulletin No. $R-497$ opens with the sentence: "As far as is known, the recent depression was unique in its disastrous repercussions upon professional groups." This, after all, is just another way of saying the depression was terribly severe, extending even into the professional groups to such an extent as to show a simultaneous unemployment of about 11 per cent of all engineers, all of the several engineering classifications suffering to about the same degree. As might be expected, there was a greater percentage of unemployment for engineers over 53 or under 27 years of age. Summary analysis number 9 of this bulletin says:

“9. The type of education the professional engi neer had received did effect variations in both the incidence and severity of unemployment. These factors were very much less for postgraduates than for engineers with other types of education. But as between enineers with first degrees in en. But in ing and those whose college course was incomplete or who had attended noncollegiate technical schools, the differentials were very slight."

Other information shows less than three per cent of the graduates of some engineering colleges unemployed at any one time during the depression years 1930-1935. No comparable data being available for the other professions, it is difficult to know just what a reasonable standard of depression unemployment should be, but there is every reason to believe that lawyers, physicians, dentists, though busy did not fare any better than engineers in regard to net income received for service rendered. It is also very certain that engineers, in that respect, fared better than skilled mechanics and other craftsmen who constitute much of our working citizenry.

Bulletin No. R-543, "Employment in the Engineering Profession, 1929-1934," shows among other things that during the five-year period of rampant unemployment, the number of engineers graduating into the profession was 25.3 per cent the number engaged in engineering in 1929. Since the nation-wide unemployment of engineers at any one time reached a maximum of 17.7 per cent, there was, even during unemployment times, a considerable amount of employment for the beginner in engineering. The number of engineering graduates, therefore, probably was not too high for normal times and the indication is that all should be needed by industry, if only persons well qualified for engineering work choose to enter the profession.

Bulletin No. R-588, "Income and Earnings in the Engineering Profession, 19291934," presents much very interesting data. Table I is part of table 3, page 7, of Bulletin No. R-588.

The table shows that in 1929 all but ten per cent of the engineers received wages equal to or better than the wages of skilled mechanics, as published in Bulletin No. 616, "Wages and Hours of Labor," which lists the pay for skilled and unskilled labor in many industries and shows mechanics' wages are $\$ 25$ to $\$ 35$ per week with occasional skilled occupations paying larger amounts.

First-degree engineering graduates start work at about $\$ 25$ to $\$ 30$ per week. Graduates with master's and doctorate degrees start at $\$ 30$ to $\$ 50$ per week, the

Table I. Comparison of Five Levels of Annual Earnings for All Professional Engineers Reporting in 1929, 1932, and 1934

(Figures derived from adjusted data as explained on page 4 of bulletin, and without regard to employment status reported or type of education)

\begin{tabular}{|c|c|c|c|}
\hline \multirow{2}{*}{$\begin{array}{c}\text { Per cent at } \\
\text { Specified } \\
\text { Income } \\
\text { Level }\end{array}$} & \multicolumn{3}{|c|}{$\begin{array}{l}\text { Annual Earnings of More Than } \\
\text { Specified Amount (Dollars) }\end{array}$} \\
\hline & 1929 & 1932 & 1934 \\
\hline 10. & $.7,466$. & 5,605 & $.5,138$ \\
\hline 25. & $.5,012$. & $.3,827$ & $.3,429$ \\
\hline 50. & $.3,412$. & $.2,574$ & $.2,286$ \\
\hline 75 . & 2,509 & 1,698 & $.1,473$ \\
\hline 90 . & $.1,878$. & $\begin{array}{l}. \\
.\end{array}$ & . 872 \\
\hline
\end{tabular}


latter amount being reserved for men of special ability. These rates of pay appear just-the mechanic or skilled laborer being paid a premium over the common labor wage in recognition of his skill and the cost of its acquirement. The wage premium for neophite engineers is a recognition of the fact that time and money have been required for college training which will enable them to become engineers rapidly, rather than as recognition of acquired proficiency as in the case of mechanics. The pay men just out of college receive, provided it keeps them from want, is relatively unimportant, as compared to opportunity for advancement in responsibility and salary. Salary advances for engineers of the United States and for lawyers of California, so far as the latter information is available, are compared in figure 1 . The curves applying to engineers are taken from chart 1 , Bulletin $R-588$. The data pertaining to the lawyers of California is from an unpublished "Digest of a Survey of the Economic and Professional Status of California Lawyers during the First Five Years of Practice," prepared in 1937 by the committee for co-operation between the law schools and the state bar.

The curves for the engineers show favorable advancement in salary with age and experience for the upper half of those in the profession, as also does the rather limited data for the lawyers. It is interesting to note the long rise in earning capacity extending unto a man's 60th year of age and $37 \mathrm{th}$ year of practice. Observation, without confirming data, creates the opinion that lawyers and physicians follow the same laws in this respect. No actual data have been made available for physicians, but an oral check with a number of them brought forth statements, all in agreement, to the effect that in the opinions of those interviewed, the curves for the engineers were, on the whole, indicative of the net salaries for physicians-the average for the physicians being perhaps a little better than the average for engineers; but less than ten per cent of the physicians have net incomes above the 10 per cent curve for engineers.

All this information seems to indicate equity in the income of engineers as compared to skilled laborers, lawyers, and physicians.

The professional men are indeed fortunate in having occupations which provide for increasing service to fellow men as years add to skill and experience, and also in having at the same time increasing incomes which grow apace with the family expenses and often continue to grow be-

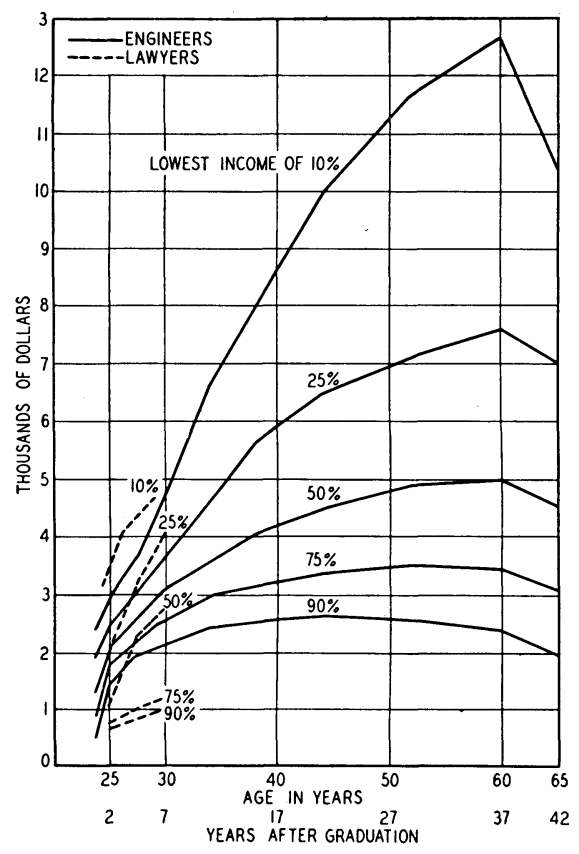

Figure 1. Earned annual income of engineers and lawyers according to age

The curves for engineers represent the findings for all the engineers of the United States. The curves for lawyers represent the findings for California lawyers admitted to the bar in 1931

yond the period required to get the children established in their own homes and occupations.

Those of our profession who disagree with these findings, particularly as they apply to engineers, have two arguments against them-one the apparent greater expenditure of money by lawyers and physicians as compared to that of the engineers, which they have witnessed. It must be borne in mind that some of the expenditure made by physicians and lawyers is for office equipment and automobiles that must be used in connection with the practice of these professions. Also it is worthy of note that the expenditures which attract attention are usually those made by the more prosperous, rather than by the representative members of the profession.

Moreover, comparisons which men make purely by observation, rather than on the basis of exact data, between the spheres of their own activity and those of others, generally result in optimistic interpretations regarding the outside spheres, with a simultaneous pessimistic appraisal of their own. "The grass on the other side of the fence is always greener."

The second objection has to do with the exactness of the data obtained from returned questionnaires as compared to that which would have been available, had every engineer in the land returned a com- plete questionnaire. A complete report, would, of course, be impossible except by absolute governmental decree ordering a census of all engineers, but the data available which came from the 52,589 engineers who properly filled out and returned the questionnaire should give a fair crosssection of the 167,268 engineers who received them.

Assuming the data used to be representative, the analysis has narrowed to two questions: (1) Why is there such great spread in income for men in the same profession who have gone through the same training courses, been subject to the same tests as to ability, and have survived the same processes of selection? (2) What are we going to do about it?

Many educators and others have often asked these questions and made surveys of industry, hoping thereby to find the answer, but all have ended with only a variety of general but authoritative statements by those who employ engineers. Some of these statements are:

Graduates of engineering colleges do not fail to reach expected goals because of lack of technical education but rather because of deficiencies in those qualities described by such terms as:

Personality

Loyalty

Patience

Humility

Breadth of interest

Business ability

Leadership

Aptitude

Promptness

Accuracy

Judgment

Proper estimate of own value

Executive ability

with sometimes the comment that there is lack of education in basic science and mathematics. All of which takes us back to a part of the definition with which we started, "it supposes as its basis the knowledge and discipline which general culture affords."

Only the last of these objections; viz., the lack of education in basic science and mathematics, will, at first thought, be charged to weakness in engineering-college curricula and training-but there is a fourfold responsibility involved in the making of an engineer which must be assumed jointly by the young man, his family, the college, and industry.

America, the land of opportunity, provides many avenues for rendering service and at the same time improving standards of living. Not the least of these are the engineering professions. Via engineering and the education provided by the engineering colleges, many men have reached 
social positions and attained economic rewards far better than those of the families from which they came. In fact, there are so few exceptions to this order of things, even among the poorer paid engineers, as to make perfectly valid some such declaration as: "Engineering is a profession through which the sons of small merchants, farmers, and laborers, as well as those of professional men and the prosperous in industry find golden opportunities to high living standards."

A large portion of the enrolled students in engineering colleges in part or entirely "work their way through." The author has, for more than a quarter of a century, co-operated with these men to make work, college courses, family budgets, and loan funds blend to the best advantage of all concerned. This blending process is not always easy, nor, though a certain amount of labor experience is desirable, is it advantageous for a student to be compelled to allot a very large part of his college time to earning money. In one college where the tuition is $\$ 300$ per year and there are relatively few scholarships, 1/6 of the undergraduate student body and $1 / 10$ of the graduate students are using NYA assistance. Nearly all the families to which these young men belong have incomes $\$ 1,200.00$ per year or less. According to the catalogue of the college in question, the minimum estimated cost per student for board and room, books, tuition, etc., but with no allowance for entertainment and clothing, is:

Students taking 21 meals in student houses per week-\$840 per year

Students taking 15 meals (going home weekends) - $\$ 740$ per year

Nonresident students- $\$ 390$ per year

The cost per student in many free-tuition colleges, when all factors are considered is practically the same. If a $\$ 1,200.00$ per-year-income family (and there are those with less) must, with the aid of the student apportion an amount equal to $2 / 3$ the family income for the bare essentials of being in college, it is obvious there is little money available for travel, hotel life, theater, dances, and other social functions, or even for church activitiesall of which have great bearing upon the phases of life which employers have declared are deficient in engineers to an extent which impairs engineering careers.

These deficiencies fortunately can all be remedied by any normal young man with capacity to complete an engineering course, if he is made aware of them, and will make an honest effort to know himself and apply the needed corrections. Keeping well is always simpler and better than curing illness, but continuing in illness is infinitely worse and sometimes inexcusable.

Being born and nurtured in an atmosphere of culture where all the graces of life are daily habits which can be acquired with little conscious effort has its advantages. When this experience has been denied the engineering students, colleges should provide clinics for correcting the deficiencies. Some of the more progressive engineering colleges have made progress in the right direction by having in their curricula a goodly proportion of cultural courses with the consequent necessity for postponement of the more special technical courses to graduate years. Industry also should not limit all its training courses for young engineers to the technique of the business, but should provide opportunity for them to learn of and correct faults which impair the rendering of the highest possible type of engineering service. College and industry together must show interest in our educational program from kindergarten on and co-operate with our engineering societies and the Engineers Council for Professional Development in extending their program for educating the public as to the requirements for being an engineer.

Industry should see to it that all who qualify as engineers be paid all the work done will warrant and should not designate as engineering, work which is not engineering, but is only high-class clerical calculating, draughting, or skilled machine operation.

Engineers should make themselves thoroughly conversant and be sympathetic with all the problems of labor, skilled and unskilled, preferably through having had actual experience as workers in both classifications. They should not make entangling commitments to either capital or labor which may interfere with their great opportunities to correlate these two great industrial factors into teams that, working together at the business of applying engineering methods, cannot be defeated.

Fortunate indeed are the youths who find their talents and choices leading them into engineering; they can have a lot of fun following one of the many paths leading to enjoyable service for their fellow men, and at the same time providing so well a means of livelihood for themselves and their families.

\section{Discussion}

L. A. Doggett (Pennsylvania State College, State College): In commenting on Professor Sorensen's paper, I would like to point out that the economic status of the engineer is different from that of either the doctor or the lawyer. The engineer's economic status is that of the hired man. By that I mean that his economic status is seldom that of a member of a board of directors (a sampling of 209 directors, 19 electrical companies, in Moody's 1933 Utilities shows 17 AIEE members). The engineer in the last analysis takes his orders from those who are not engineers. Why is this? Primarily I believe it is due to a MYTH that has been fostered for the last 25 years, a myth which has as one of its tenets that the engineer must stick strictly to his volts and amperes. For example, it is perfectly orthodox for the engineer to study and investigate switches, bushings, power factor, line interruptions, etc. It is entirely orthodox to study line interruptions due to lightning, but when a certain switch was opened on the Connecticut state line the day after the holding company bill was signed, if thereupon we study the reasons for this line interruption, if we study this holding company bill, if we study the 70 odd volumes of the report of the Federal Trade Commission on utility corporations; then we are no longer orthodox, we are heretics; for does not the code of the AIEE technical program committee, 1934 edition, say "rate making, project financing, . . . . ., utility regulation" are "subjects not suitable for Institute presentation." Since reading that statement these subjects have taken on for me the glamour of the forbidden. I have taken a peculiar pleasure in studying these subjects which are supposed to be taboo for engineers. With the same wicked pleasure that a boy might take in slipping out of church, I "snuk" out of the Tuesday morning AIEE meeting and went down to 18th and Pennsylvania avenues to listen in on two Securities and Exchange Commission hearings. In each hearing some sort of an exploratory operation was being performed on a holding company. There I could hear all sorts of "verboten" words, such as voting trust agreement, underwriters commissions, voting stock, etc., etc.

In conclusion I want to recommend a wider freedom for AIEE members, a freedom which would allow them, when studying any electrical problem, to follow up the investigation regardless of where it leads them, whether into the field of law, history, economics, medicine, politics, or archaeology, a freedom to make their investigations and publish their results in ElECTRICAL Engineering. For example, if an engineer starts out to study filters and networks, goes thence into telephone traffic problems, thence into commercial phases of the telephone art, and finally into a study of the recent Government investigation of the telephone industry; if he finds this investigation unfair in its procedures and in its conclusions, he ought to have the same right to publish these findings as to publish something about. filters. And these latter findings deal with a subject which has a very powerful effect on the economic status of the electrical engineer. I would, however, qualify this freedom by specifying that the main title of any AIEE article should be of an electrical engineering nature and that the nonengineering matter might appear as paragraphs subsidiary to the main title.

When the electrical engineer regains his freedom of speech, then will his economic 
status far transcend his present status which as Professor Sorensen points out isn't so bad.

E. E. George (Tennessee Electric Power Company, Chattanooga): The paper by Professor Sorensen is of unusual interest to the engineering profession at the present time. There have been very few papers on this subject presented to the AIEE. Professor Sorensen's statements appeal to the reader on account of the broad viewpoint taken and the supporting facts presented. It is interesting and encouraging to note that the engineer both in normal times and during depression fares as welt as other professional men.

Few people would contest Professor Sorensen's comment that the career of many engineers would be smoother if they were more experienced in co-operation and were better equipped with the social graces. Nevertheless, it would be extremely discouraging to see more emphasis placed on co-operation and culture unless these are subordinated to learning "the value of a dollar." Notwithstanding the current political tendency to consider hard work and meager income as an unfair handicap and a social injustice, it is more and more becoming apparent that practically every great contribution to civilization has come from those who were required early in life to work hard through necessity or who had the responsibility of providing jobs for others (without impairment of capital) before they reached middle age. Most of the greatest technical improvements have been made by those who took up engineering in order to make a living and not as a hobby or to keep out of idleness. It is believed that the majority of engineers feel that the most important qualification an engineer can have is the breadth of economic judgment and the innate sense of fairness which is quickly acquired by those who have to earn their own living or to have to meet a payroll from which others earn a living.

It is becoming more and more apparent that if engineers are to improve their economic status both business and government must be controlled and operated by men who "know the value of a dollar."

It is misplaced emphasis for the technical school or AIEE to encourage the young engineer to develop a better induction motor if there is no market for that motor when it is built and if inferior motors built several years before and with their cost already amortized are idle because of governmental interference with economics. It is likewise futile to expect engineers to make technical advances if the majority of them have to be more concerned with continuity of employment than with any other problem. The AIEE cannot maintain its high position as a leading professional body if it continues to take no important position toward fact finding in the public ownership controversy and in similar industrial problems which are now occupying the minds of a large percentage of its members. To say that public enlightenment on the technical and economic phases of these problems must come from the action of engineers as individuals is to deny the value of co-operation and organization. Without imposing on the rights of any minority or being unfair to Institute members who are public employees the Institute ought to be able to find a middle-of-the-road course with committees of highly respected engineers assigned to a program of fact finding which would help the majority of its members immediately and ultimately further the program of technical development to the final benefit of all its members.

In view of the conservative attitude taken by the AIEE in dealing with this and with related problems, it is suggested that readers should note the widely different attitude prevailing in the American Society of Civil Engineers, as reported in the Bulletin of the American Engineering Council for June 1938.

R. W. Sorensen: The remarks made by Professor L. A. Doggett and by E. E. George are very expressive of the opinion of many Institute members and are, indeed, valuable additions to the paper. I think, however, that Professor Doggett has missed a point regarding the distinction between the business which uses the products of engineering and the economic phases of that business which have to do with the work of an engineer. I do not interpret any AIEE code to mean that the Institute publications are closed to a discussion of scientific principles of rate making, utility regulation, or perhaps even project financing, if those discussions adhere to Professor Doggett's own limitation that any AIEE article should be of an electrical engineering nature.

Professor Doggett seems to think there is something wrong because the 209 directors of 19 companies in Moody's 1934 Utilities include only 17 AIEE members. This statement in itself does not indicate, per se, there is something wrong without further analysis which would include the proportion of AIEE members to non-AIEE members who are interested in the utility business as stockholders and who have, therefore, the right to determine how the business shall be conducted. In fact I would like to cite from memory some approximate figures published in Forbes Magazine in response to an urgent request for an analysis of leaders in industry according to professions. After a careful canvass of all factors involved, Forbes published the following figures: About 21 out of 59 leading men of the world, in this respect, were trained as business men, about 17 arose to their positions through the legal profession, about 12 through the engineering profession and the balance, 5 , 3 , and 1 , respectively, through training in other professions which were listed, but the names of which I cannot recall. Considering the relative newness of the engineering profession to the field of business and the legal profession, I am inclined to think the proper number of engineers have achieved places among this limited group of the world's outstanding men selected by the Forbes Magazine. Furthermore I have personally never discovered any evidence of lack of freedom of speech for engineers. Is it any more reasonable to use the time of engineering meetings and the pages of engineering publications for the preaching and publication of sermons and political speeches than it is to use the pulpit for the presentation of technical papers? On the other hand I am sure any engineer who wished to preach a sermon in keeping with the purpose of a house of worship, would not be forbidden freedom of speech.

I think, as an engineer, I would disagree with $\mathrm{Mr}$. George and say it is the business of technical schools or the AIEE to encourage the young engineer to develop a better induction motor even if induction motors were never used; but, of course, I must acknowledge quite readily that much of the enthusiasm for such work or the opportunity for such work will be lost if such development cannot receive recognition in the way of finding purchasers for the improved induction motors.

Again Mr. George said "Without imposing on the rights of any minority or being unfair to Institute members who are public employees, the Institute ought to be able to find the middle-of-the-road course with committees of highly respected engineers assigned to a program of fact finding which would help the majority of its members immediately, and ultimately further the progress of technical development to the final benefit of all its members." I, speaking as an individual, am of the opinion that whenever engineers on opposite sides of controversial subjects can agree as to what are the facts, the technical papers committee will not stand in the way of the publication of such facts. 